\title{
Biology of the ornamental cyprinid fish Danio dangila (Hamilton, 1822) from the North-eastern hill region of India
}

\author{
B. K. MAHAPATRA ${ }^{1}$, K. VINOD ${ }^{2}$ AND W. S. LAKRA ${ }^{3}$ \\ ${ }^{1}$ Research Centre of ICAR-Central Institute of Fisheries Education, Kolkata, Sector-V, Salt Lake City \\ Kolkata - 700 091, West Bengal, India \\ ${ }^{2}$ Calicut Research Centre of ICAR-Central Marine Fisheries Research Institute, West Hill P.O. \\ Calicut - 673 005, Kerala, India \\ ${ }^{3}$ ICAR-Central Institute of Fisheries Education, Seven Bungalows, Versova, Mumbai - 400 061, Maharashtra, India \\ e-mail: bkmahapatra2007@yahoo.co.in
}

\begin{abstract}
The moustache danio Danio dangila (Hamilton, 1822) is one of the most popular native ornamental fishes of the North-eastern hill region of India. The species needs immediate attention owing to its reduced abundance in the wild. The length-weight relationship of $D$. dangila indicated an isometric growth in general and was found to follow the cube law. The L-W relationships derived for the species were: $\log \mathrm{W}=-5.009+3.00 \log \mathrm{L}$ (male and female combined); $\log \mathrm{W}=-5.542+3.31 \log \mathrm{L}$ (male) and $\log \mathrm{W}=-5.462+3.26 \log \mathrm{L}$ (female). The $41-50 \mathrm{~mm}$ size group was found to be predominant $(44.25 \%)$ in the wild. The fish predominantly feeds on phytoplankton $(97.12 \%)$, with Myxophycea forming $68 \%$, followed by Zygnemophyceae 25\%, Ulvophyceae 3\%, Zygnematophyceae 2\%, Cryptophyceae $1 \%$ and Bacillariophyceae $1 \%$. The major zooplankton group in the diet was Rotifera. Nematodes and other similar worms also formed a part of their diet. The sex ratio (female: male) estimated was 1:1.77. The gonadosomatic index (GSI) for gravid females ranged from 2.55 to 24.12 with an average value of 7.65 . The minimum and maximum fecundity were 400 and 2000 in females having a length of 52 and $64 \mathrm{~mm}$ and weight of 2.52 and $3.15 \mathrm{~g}$ respectively.
\end{abstract}

Keywords: Danio dangila, Fecundity, Feeding, Length-weight relationship, North-eastern hill region

The genus Danio comprises many species of danionins familiar to aquarists and among them, the moustache danio Danio dangila (Hamilton, 1822) is one of the most popular ornamental fish, both locally and globally (Vinod et al., 2001). This species is characterised by an olive colouration dorsally with silvery sides and several narrow blue lines, which are discontinuous anteriorly forming a beautiful network in the first half of the body (Fig. 1). The anal fin has two to three blue stripes and there is a dusky spot at the upper angle of the gill opening.

D. dangila is an active swimmer and generally move on the surface. Their bright silvery appearance and

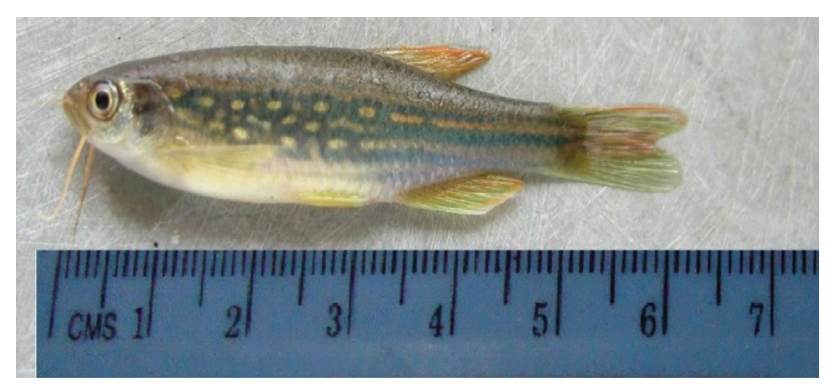

Fig. 1. The moustache danio Danio dangila bands are unique features attracting hobbyists and the species fetches ₹12/- and US\$ 1.50 per pair in the local and international markets respectively. Both sexes of this fish have almost the same colouration and have equal acceptance in the ornamental fish trade. They are hardy and compatible with other species in a community aquarium tank. This species is distributed in India, Bangladesh, Nepal, Bhutan and Myanmar (Talwar and Jhingran, 1991). The name "danio" comes from the Bengali name dhani, meaning "rice field". They commonly inhabit paddy fields, ponds and small streams and are found to be distributed in all the North-eastern states of India (Sen, 2000; Mahapatra et al., 2004). West Bengal and North-eastern states are the main contributors to the wild caught fishes exported from the country (Mahapatra et al., 2006). Although the demand for this fish is high in the ornamental fish trade, presently the requirement is being fulfilled only from the natural collection (Mahapatra et al., 2001). This fish is assessed as "Least Concern (Lc)" in the IUCN Red List and has a wide distribution (Vishwanath, 2010). But recently, the overexploitation of this species from the wild resulted in depletion of the natural stocks. This calls for an urgent need to breed this fish in captivity to meet the growing 
demand and also as a formal step towards conservation (Mahapatra et al., 2004; Mandal et al., 2007; Dey et al., 2014). The present study was undertaken to understand the biology of this species which is very much essential for captive breeding under controlled conditions.

Monthly samples of $D$. dangila were collected during April 2000 to December 2004 from streams and paddy fields of Meghalaya, North-eastern India. The fishes were collected from terraced paddy fields using a bamboo trap locally called "roh" (Fig. 2a) and from streams and swampy areas using a bamboo-made gear locally known as "chekke" (Fig. 2b). Operation of these traditional gears can be regarded as an eco-friendly method of fish collection, as these gears do not cause destruction to the habitat and the fishes collected are also not injured.

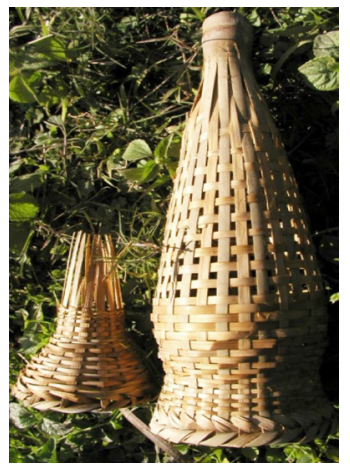

(a)

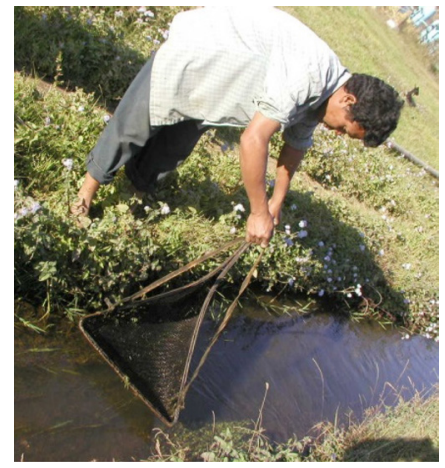

(b)
Fig. 2. Gears used locally in Meghalaya for collecting weed fishes including $D$. dangila. (a): Roh, (b): Chekke
A total of 175 specimens were examined for analysing the length-weight relationship. The relationship was established following the formula of Le Cren (1951) by transformation into a straight-line equation, $\log \mathrm{W}=\log \mathrm{a}+\mathrm{b} \log \mathrm{L}$. The length-weight $(\mathrm{L}-\mathrm{W})$ relationships derived for both the sexes of $D$. dangila separately and for combined sexes are given in Table 1 . The length and weight of the fishes ranged from 22.5 to $71 \mathrm{~mm}$ and from 0.12 to $3.68 \mathrm{~g}$ respectively. Regression model was fitted for length and weight of male, female and combined sexes separately (Table 1). For a fish which maintains its shape throughout its life, the value of regression coefficient will be '3' (Varghese, 1961; Talwar, 1962) and deviation from ' 3 ', indicates allometric growth. The length-weight data are presented in the form of scatter diagram (Fig. 3a, b, c) which shows that the relationships are linear. In the present study, $r$ values obtained were $0.982,0.974$ and 0.981 for male, female and combined sexes respectively indicating good fit of the model in all cases. The functional form of relationship between L-W of the species were fitted as: $\log \mathrm{W}=-5.009+3.00 \log \mathrm{L}$ for combined sexes, $\log \mathrm{W}=-5.542+3.31 \log \mathrm{L}$ for male and $\log \mathrm{W}=-5.462+3.26 \log \mathrm{L}$ for female. The ' $\mathrm{b}$ ' value of male $(b=3.315)$, female $(b=3.259)$ and combined sexes $(\mathrm{b}=3.00)$ indicated isometric growth for D. dangila. In Brachydanio rerio, Mahapatra and Lakra (2014) observed negative allometric growth in male, positive allometric growth in female and isometric growth in combined sexes and stated that this species do not strictly follow the cube law.

Table 1. Length-weight relationship of Danio dangila among different groups, with their respective value of correlation coefficient (r)

\begin{tabular}{|c|c|c|c|c|}
\hline Group & Sample size & Size range & Regression equation & $\mathrm{r}$ \\
\hline Male & 20 & $35.00-62.00 \mathrm{~mm}, 0.39-2.40 \mathrm{~g}$ & $\log \mathrm{W}=-5.542+3.315 \log \mathrm{L}$ & 0.982 \\
\hline Female & 45 & $34.00-71.00 \mathrm{~mm}, 0.37-3.68 \mathrm{~g}$ & $\log \mathrm{W}=-5.0+3.259 \log \mathrm{L}$ & 0.974 \\
\hline Combined & 175 & $22.50-71.00 \mathrm{~mm}, 0.12-3.68 \mathrm{~g}$ & $\log W=-5.009+3 \log L$ & 0.981 \\
\hline
\end{tabular}

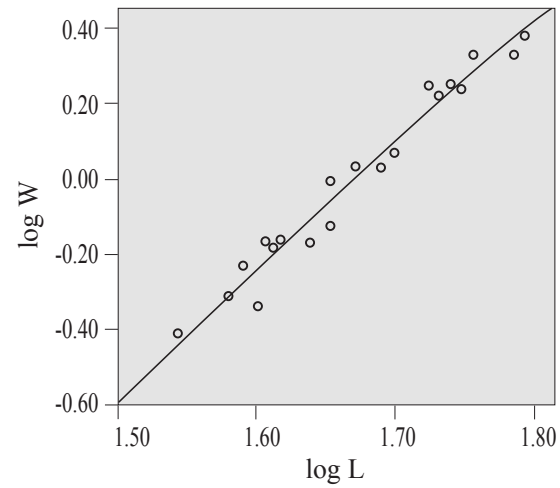

(a)

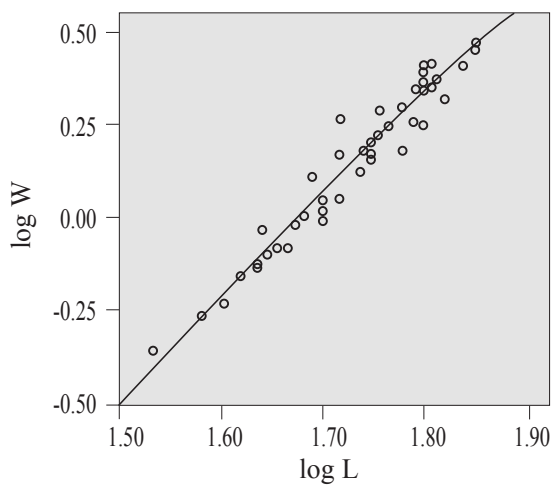

(b)

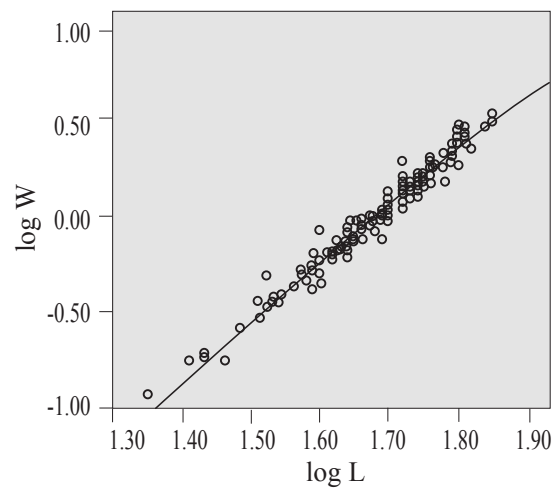

(c)

O Observed, - Logarithmic

Fig. 3. Length-weight relationship of $D$. dangila. (a): Male, (b): Female, (c): Combined sexes 


\section{Distribution in different size}

A total of 339 specimens of $D$. dangila were examined for estimating the distribution of different size groups. The variation in the number of fishes recorded in different size groups are presented in Table 2. The size group of 41 to $50 \mathrm{~mm}$ was found to be predominant $(44.3 \%)$ over the other size groups. Larger sized fishes of $61 \mathrm{~mm}$ and above were found to be very rare.

Table 2. Frequency distribution of different size groups of Danio dangila recorded during the study period

\begin{tabular}{lll}
\hline Size groups $(\mathrm{mm})$ & No. of fishes & Percentage contribution \\
\hline$<30$ & 12 & 3.5 \\
$31-40$ & 79 & 23.3 \\
$41-50$ & 150 & 44.3 \\
$51-60$ & 65 & 19.2 \\
$61 \&$ above & 33 & 9.7 \\
\hline
\end{tabular}

Gut contents of 50 specimens were analysed for studying the food habits employing percentage occurrence method (Hynes, 1950). Food items were identified up to major taxonomic groups. The moustache danio was observed to feed on both phytoplankton and zooplankton; with a preference to the former. A similar observation was made in B. rerio by Mahapatra and Lakra (2014). The mouth of $D$. dangila is terminal and oblique; with two pairs of barbels (maxillary and rostral) and there are four pairs of well-developed gill arches. The important groups of phytoplankton in the diet include diatoms like Navicula sp., Fragilaria sp., Asterionella sp. and desmids like Cosmarium sp., Eaustrum sp. and Closterium sp. Occasionally, zooplankton like Philodina sp., Lecane sp., Testudinella sp., Lepedella sp. and Arcella sp. were also encountered. Nematodes and similar worms also formed a part of their diet. In the gut, phytoplankton formed $97.12 \%$ and the rest were zooplankton. Myxophyceans were observed as the most abundant group with an average of $68 \%$ (Fig. 4) and encountered on a regular basis in the gut contents throughout the study period. Navicula sp., Fragilaria sp. and Asterionella sp. were the dominant genera of Myxophyceans recorded. Zygnemophyceae was found to be the second most abundant group contributing an average of $25 \%$ forming the dominant genera among them. Ulvophyceae, Zygnematophyceae, Cryptophyceae and Bacillariophyceae have been found to constitute $3,2,1$ and $1 \%$ respectively. The major zooplankton group was represented by Rotifera which comprised Lecane sp., Lapedella sp., Aneuraeopsis sp., Asplanchna sp., Lepadella sp. and Testudinella sp.

In $D$. dangila, the females were found to be broader while the males were slender in appearance. Females can be distinguished from their male counterparts

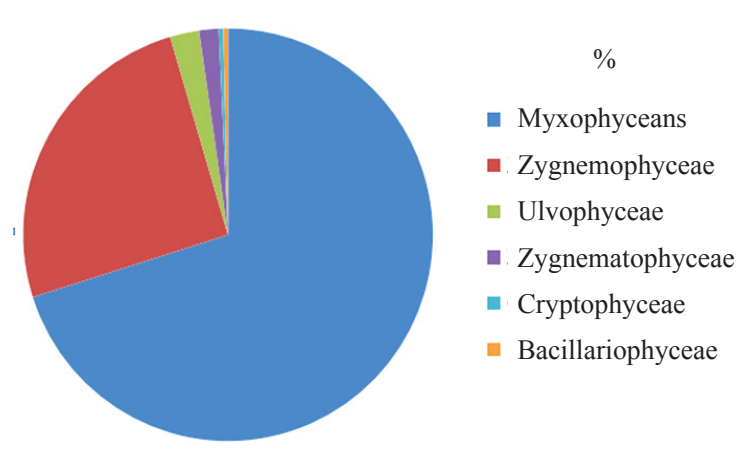

Fig. 4. Composition of phytoplankton in the gut content of Danio dangila

during the breeding season from their swollen belly. The minimum length and weight at first maturity was $52 \mathrm{~mm}$ and $2.52 \mathrm{~g}$ respectively in females. The length at which $50 \%$ of the females were mature was considered as the length at first maturity. The attainment of first maturity occurs when male is $5+$ months and female is $6+$ months old. The sex ratio was studied using Chi-square test $\left(\mathrm{X}^{2}\right)$, following the equation of Fisher (1970) and the ratio (female : male) obtained was 1 : 1.77. The gonadosomatic index (GSI) for females was estimated as the ratio of the weight of gonad to body weight. The GSI for gravid females ranged from 2.55 to 24.12 with an average of 7.65 . The fecundity was estimated from 30 specimens by counting the number of mature ova from a known weight of subsamples collected from the anterior, posterior and middle portions of both the ovaries followed by calculating the total number of mature ova in the ovary following Grimes and Huntsman (1980). The minimum number of ova produced was 400 in a female having total length (TL) of $52 \mathrm{~mm}$ and weight of $2.69 \mathrm{~g}$ while a maximum of 2000 nos. of ova was produced by a female having TL of $71.0 \mathrm{~mm}$ weighing 9.75 g. B. rerio which shares a similar habitat with $D$. dangila is comparatively smaller in size with a fecundity ranging from 215 (fish having TL of $29 \mathrm{~mm}$ and weighing $0.2 \mathrm{~g}$ ) to 2836 numbers (fish having TL of $49 \mathrm{~mm}$ weighing $1.81 \mathrm{~g}$ ) (Mahapatra and Lakra, 2014). The average fecundity recorded was 882 and the number of mature eggs per gram of body weight (fecundity factor) ranged from 141 to 702 with an average of 306 (Table 3).

Since the population of moustache danio in the wild is declining gradually, it is essential to attempt breeding programmes in captivity for conservation of the species. The information generated on the biology of the species from the present study would definitely help in attempts for artificial propagation of the species in captivity. 
Table 3. Fecundity observed from 30 gravid females of Danio dangila

\begin{tabular}{llllll}
\hline & Total length $(\mathrm{mm})$ & Weight $(\mathrm{g})$ & Ovary weight $(\mathrm{g})$ & Fecundity & Fecundity factor (No. of ova per g body wt.) \\
\hline Average & 64.03 & 3.03 & 0.27 & 882 & 305.85 \\
Maximum & 71 & 9.75 & 1.85 & 2000 & 701.90 \\
Minimum & 52 & 2.69 & 0.08 & 400 & 141.33 \\
\hline
\end{tabular}

\section{Acknowledgements}

The authors are greatly indebted to Dr. Gopal Krishna, Director, ICAR-CIFE, Mumbai for providing facilities to carry out the research work.

\section{References}

Dey, S., Ramanujam, S. N. and Mahapatra, B. K. 2014. Breeding and development of ornamental hill stream fish Devario aequipinnatus (McClelland) in captivity. Int. J. Fish. Aquat. Stud., 1(4): 1-7.

Fisher, R. A. 1970. Statistical methods for research workers, $14^{\text {th }}$ edn. Oliver and Boyd, Edinburg, $362 \mathrm{pp}$.

Grimes, C. B. and Huntsman, G. R. 1980. Reproductive biology of the vermilion snapper, Rhomboplites aurorubens from North Carolina and South Carolina. Fish. Bull., 78: 137-146.

Hynes, H. B. N. 1950. On the food of the freshwater sticklebacks (Gastrosteus aculeatus and Pygosteus pungitius) with a review of the methods used in the study of food fishes. J. Anim. Ecol., 19: 36-58.

Le Cren, E. D. 1951. The length-weight relationship and seasonal cycle in gonad weight and condition in the perch (Perca fluviatilis). J. Anim. Ecol., 20: 201-219.

Mahapatra, B. K. and Lakra, W. S. 2014. Biology of Brachydanio rerio (Hamilton, 1822) from North-eastern hill region, India. J. Inland Fish. Soc. India, 46(2): 64-70.

Mahapatra, B. K., Vinod, K., Mandal, B. K. and Bujarbaruah, K. M. 2006. Ornamental fisheries in North-eastern India. Research Bulletin No. 49, ICAR Research Complex for NEH Region, Umiam, Meghalaya, 48 pp.

Mahapatra, B. K., Vinod, K. and Mandal, B. K. 2004. Ornamental fish of North-eastern India - its distribution and conservation status. Environ. Ecol., 22(3): 674-683.

Mahapatra, B. K., Vinod, K. and Mandal, B. K. 2001. Ornamental Fishery - A new horizon for R \& D in Meghalaya. National
Seminar on Approaches for increasing agricultural productivity in hill and mountain ecosystem, 18-20 October, 2001, ICAR Research Complex for NEH Region, Umiam, Meghalaya.

Mandal, S., Mahapatra, B. K., Tripathi, A. K., Verma, M. R., Datta, K. K. and Ngachan, S. V. 2007. Agribusiness opportunities of ornamental fisheries in North-eastern region of India. Agric. Econ. Res. Rev., 20 (Conference Issue): 471-488.

Sen, N. 2000. Occurrence, distribution and status of diversified fish fauna of North-east India. Occasional paper. In: Ponniah, A. G. and Sarkar, U. K. (Eds.), Fish biodiversity of North-east India. NATP Publication. National Bureaeu of Fish Genetic Resources, Lucknow, p. 31- 48.

Talwar, P. K. 1962. A contribution to the biology of the halfbeak, Hyporhamphus georgii (Cuv. and Val.) (Hemiramphidae). Indian J. Fish., 9(1): 168-196.

Talwar, P. K. and Jhingran, A. G. 1991. Inland fishes of India and adjacent countries, vol 1, Oxford \& IBH Publishing Co. Pvt. Ltd. New Delhi, 366 pp.

Varghese, T. J. 1961. Observations on the biology of Raconda russelliana (Gray). Indian J. Fish., 8(1): 96-106.

Vinod, K., Mahapatra, B. K. and Mandal, B. K. 2001. Brachydanio rerio (Hamilton) and Danio dangila (Hamilton) - promising species for ornamental fisheries in Meghalaya and strategies for judicious exploitation. Workshop on Integration of fish biodiversity conservation and development of fisheries in North-eastern region through community participation; National Bureaeu of Fish Genetic Resources, Lucknow and the North-eastern council (NEC), 12-13 December 2001, Shillong, Meghalaya, p. 225-230.

Vishwanath, W. 2010. Danio dangila. The IUCN Red list of threatened species 2010. $<$ www.iucnredlist.org $>$ (Accessed 6 August 2016). 